\title{
Natura@economía
}

ISSN 2226-9479 (Versión electrónica)

\section{El aprovechamiento del Tratado de Libre Comercio entre la República del Perú y la República de Chile desde la mirada del agronegocio}

The explotion of the Free Trade Agreement Signed between the Republic of Peru and the Republic of Chile from the perspective of the peruvian agribusiness

\author{
Roberto J. Morales M. ${ }^{1}$ \\ ${ }^{1}$ Instituto Superior de Comercio Exterior ADEX, Lima, Perú. ID de ORCID 0000-0001-5241-7615, jmoralesm@adexperu.edu.pe
}

Recepción: 01/01/2021; Aceptación: 15/05/2021

\section{Resumen}

El objetivo del estudio fue evaluar el grado de aprovechamiento del Tratado de Libre Comercio (TLC) suscrito entre Perú y Chile desde la mirada de los agronegocios. Los objetivos específicos fueron determinar las partidas arancelarias aprovechadas y las no aprovechadas. La investigación es cuantitativa, de alcance descriptivo, básica, con un diseño no experimental longitudinal. La técnica fue la observación directa, estructurada e individual, analizando el período comprendido entre los años 2009 al 2015 con las estadísticas del Trade Map, SUNAT y MINCETUR sobre el comportamiento de las partidas de los 24 capítulos del Sistema Armonizado de Designación y Codificación de Mercancías, vinculados a los agronegocios. La firma del Tratado trajo beneficios, más allá de la liberación arancelaria. Conforme a los resultados, se concluye que el TLC se podría aprovechar mucho más, se desaprovechan 2411 partidas, solo 88 se aprovechan y 51 partidas incrementaron la oferta exportable. Se requiere continuar investigando y profundizar con el estudio de las Subpartidas, las que no se exportan o disminuyeron, a fin de encontrar nuevas oportunidades de negocio y ampliación de la oferta exportable, considerar políticas que incentiven las exportaciones con valor agregado, propiciar una mayor la difusión de los beneficios del Tratado, fortalecer las cadenas asociativas productivas agrarias, desarrollar programas de capacitación a productores agropecuarios y exportadores para difundir las ventajas del TLC y sean mejor aprovechados todos los nichos de negocio.

Palabras clave: Agronegocios; Chile; Exportaciones; Tratado de Libre Comercio; Partidas Aprovechadas; Partidas Desaprovechadas.

Forma de referenciar el artículo: Morales, R. (2021). El aprovechamiento del Tratado de Libre Comercio entre la República del Perú y la República de Chile desde la mirada del agronegocio, Natura@economía, 6(1), 1-14. http:// dx.doi.org/10.21704/ne.v6i1.1728 


\begin{abstract}
The objective of the study was to evaluate the degree of use of the Free Trade Agreement (FTA) signed between Peru and Chile from the point of view of agribusiness. The specific objectives were to determine the tariff items used and not used. The research is quantitative, descriptive in scope, basic, with a longitudinal non-experimental design. The technique was direct, structured and individual observation, analyzing the period from 2009 to 2015 with statistics from the Trade Map, SUNAT and MINCETUR on the behavior of the items in the 24 chapters of the Harmonized System of Designation and Coding of Goods, linked to agribusiness. The signing of the Treaty brought benefits, beyond the tariff liberalization. According to the results, it is concluded that the FTA could be used much more, 2411 items are wasted, only 88 are used and 51 items increased the exportable supply. It is necessary to continue researching and deepen the study of the Subheadings, those that are not exported or decreased, in order to find new business opportunities and expand the exportable offer, consider policies that encourage exports with added value, promote greater dissemination of the benefits of the Agreement, strengthen the agricultural productive associative chains, develop training programs for agricultural producers and exporters to disseminate the advantages of the FTA and make better use of all business niches.
\end{abstract}

Keywords: Agribusiness; Chile; Exports; Free Trade Agreement; used items; wasted items.

\section{Introducción}

En la búsqueda de antecedentes, encontramos los trabajos sobre la administración del Tratado de Libre Comercio (TLC) firmado entre la República del Perú y la República de Canadá de Morales (2020). Asimismo, se encontróla investigación sobre la administración del TLC entre la República del Perú y la Unión Europea desde la mirada de los agronegocios. El caso de Alemania de Morales (2018).

Sobre esta base académica, nació elanálisis del Tratado de Montevideo, donde las Repúblicas de Perú y Chile convinieron celebrar el Acuerdo de Complementación Económica (ACE N. 38). Según Ccoa (2017, pp. 17-18) "contempló la desgravación de 6930 partidas (NALADISA 96) arancelarias". Sin embargo, en enero del 2005, los representantes de ambos gobiernos decidieron ampliarlo. El Acuerdo fue suscrito el 22 de agosto de 2006 y entro en vigencia el $1^{\circ}$ de marzo de 2009.

Según datos de PROMPERU (2011) "Chile es un mercado de 17,1 millones de consumidores que concentra más de untercio de su población en la capital del país", ubicando al país fronterizo en una excelente posición para recibir nuestras exportaciones, "Este país representa una de las economías más sólidas y orientadas al libre mercado en la región, así como un modelo económico estable para los inversionistas extranjeros".

Rodríguez (2016) planteó que entre el período de 1998 y el 2011, "el intercambio bilateral tuvo un crecimiento de $702 \%$, a una tasa anual de 17\%". Más adelante afirmó, "Esto ha colocado a Chile como el sétimo país dentro de destino de las exportaciones del Perú al mundo, y el primero en Latinoamérica". Sin duda alguna, la firma de un TLC con Chile era necesaria para liberar el comercio de bienes y servicios, así como aprovechar las oportunidades y facilidades del mercado vecino.

Al respecto, Faerlie (2010) planteó respecto al TLC con Chile, "el Perú siguió desde un primer momento un acuerdo más ambicioso con formato típico de TLC Norte-Sur”.

MINCETUR (2019) afirmó "En la actualidad Chile posee 26 acuerdos comerciales en vigencia, lo cual le permite comercializar bienes y servicios con 64 distintos mercados, que representan el 64,10\% de la población mundial y el $86,30 \%$ del PBI 
global". En efecto, esta inigualable condición permite al vecino del sur perfeccionar el intercambio comercial y especializarlo en los productos del campo, en los agronegocios.

Faerlie (2010) demostró que "más del 60\% de las exportaciones peruanas a Chile son productos tradicionales, mientras que el $40 \%$ pertenece al sector no tradicional"; es muy similar a la sostenida con los países del norte de Estados Unidos y la UE. Sin embargo, según MINCETUR (2019) las exportaciones no tradicionales peruanas al mercado chileno en el sector agropecuario han disminuido siendo los principales productos son: "fideos y pastas alimenticias, palta fresca, cerveza, aceituna en salmuera, pulpa de frutas cocidas y congeladas, principalmente con $23 \%$ ".

De esta manera, por la importancia que reviste este Acuerdo, se desarrolla el presente trabajo ante la carencia investigaciones sobre el análisis del TLC y el desarrollo de agronegocios. La investigación aporta nuevos nichos y oportunidades de negocio del mercado chileno para productos peruanos que no se exportan, a pesar de la eliminación de barreras arancelarias. Los resultados del estudio permiten pronosticar el aprovechamiento o desaprovechamiento de las partidas del Acuerdo, ampliar la oferta exportable, en virtud a las estadísticas que brindan las diversas herramientas de análisis estadísticos del comercio exterior. Finalmente, el objetivo general del presente estudio fue evaluar el grado de aprovechamiento del Tratado de Libre Comercio suscrito entre el Perú y Chile desde la mirada de los agronegocios. Los objetivos específicos son: a) determinar las partidas arancelarias aprovechadas por los exportadores peruanos; y b) describir las partidas arancelarias desaprovechadas del Acuerdo.

\section{Materiales y métodos}

La investigación es cuantitativa porque la muestra, la recolección y el análisis de datos son fases realizadas en simultáneo, a través del uso de datos estadísticos. Además, es una investigación básica al incrementar el conocimiento sobre el objeto de estudio; posee un diseño no experimental longitudinal porque los hechos ya ocurrieron (Hernández, Fernández y Baptista, 2010); y se observó el fenómeno en su contexto natural para luego analizarlo (Hernández et al., 2010). El alcance es descriptivo y analizó la exportación de productos peruanos a Chile, utilizo el método descriptivo porque midió el grado de aprovechamiento o no de las diversas partidas del Acuerdo, a través de las estadísticas de exportación de los productos agrícolas y agroindustriales peruanos a Chile, el uso de beneficios y oportunidades, así como ampliar la oferta exportable, en función a las estadísticas que brindan las diversas herramientas de análisis estadísticos de las secciones del sistema armonizado. La técnica utilizada fue la observación del comportamiento de las partidas de los 24 capítulos de las dos secciones del sistema armonizado de preferencias arancelarias vinculadas a los agronegocios. Por sus propias características, se utilizó la técnica de observación directa, estructurada e individual. El período analizado comprende desde el año 2009 hasta el 2015. Las fuentes usadas fueron páginas web institucionales y las herramientas de análisis estadísticos del comercio exterior peruano, Trade Map, MINCETUR y SUNAT. Se realizaron indagaciones sobre las investigaciones locales sobre el objeto de estudio, encontrándose algunas investigaciones sobre diversos TLC firmados por el Perú con Chile, Estados Unidos, Canadá, con otros países y bloques económicos, pero ninguno sobre el objeto de estudio específico, en el período investigado.

\section{Resultados y discusión}

En el 2015, Perú exportó a Chile US\$1,069.123 en comparación al año 2014, con un decrecimiento de $30 \%$, según la Tabla 1 , pero se observa un crecimiento significativo respecto a frutas y frutos comestibles, cortezas de cítricos y melones, cereales, harina, almidón, etc., respecto al 2014. 
Tabla 1. Principales productos exportados a Chile.

\begin{tabular}{lccc}
\hline \multicolumn{1}{c}{ Producto } & $\mathbf{2 0 1 4}$ & $\mathbf{2 0 1 5}$ & $\begin{array}{c}\text { Var. \% } \\
\mathbf{1 4 - 1 5}\end{array}$ \\
\hline Todos los productos. & 1537202 & 1069123 & -30 \\
Minerales, escorias y cenizas & 484588 & 254773 & -47 \\
Residuos, desechos de la industria de alimentos, forraje & 121906 & 46648 & -62 \\
Combustibles minerales, aceites, productos de dest & 187772 & 43257 & -77 \\
Animales, grasas y aceites vegetales, productos de cor & 66817 & 37946 & -43 \\
Frutas y frutos comestibles, cortezas de cítricos, melón & 18729 & 37661 & 101 \\
Manufacturas de hierro o acero & 34678 & 30204 & -13 \\
Papel y cartón, artículos de pulpa, papel y cartón & 29720 & 26043 & -12 \\
De cereales, harina, almidón, preparaciones y productos & 22594 & 24544 & 9 \\
\hline
\end{tabular}

Fuente: Trade Map (2016). En miles de dólares

La balanza comercial con Chile tuvo un crecimiento a partir del año 2009 hasta el 2012, año en que llegó a un pico de US\$ 785,761 , luego presentó una caída, respecto a los años anteriores, con saldo negativo para el 2015 de US\$ -141,190.

El Perú es un país cuyo intercambio de mercancías con otros países se vuelve cada vez más intenso con el objetivo de eliminar las barreras comerciales que impiden el libre acceso recíproco de bienes y servicios. Este objetivo lo alcanza con los TLC. Ccoa (2016) afirmó "Este TLC reviste gran importancia para el Perú, pues Chile es uno de sus principales socios comerciales y de inversiones". Asimismo, León (2013) sostuvo que los productos chilenos ingresaban a Japón con tasas menores a la de los productos peruanos "hasta que Perú firmó un acuerdo con dicho país".

La Tabla 2 muestra los años de liberación y partidas beneficiadas de la siguiente manera: (D-0) se liberaron automáticamente 2582 partidas, 486 de agronegocios; (D-5) liberó 2420 partidas, 504 de agronegocios; (D-10) liberó 676, 190 de agronegocios; la (D-15) beneficio 261 partidas, 104 de agronegocios y (D-18) liberó 24 partidas, 14 pertenecen a los agronegocios.

Tabla 2. Partidas arancelarias beneficiadas.

\begin{tabular}{ccc}
\hline $\begin{array}{c}\text { Cronograma } \\
\text { de liberación }\end{array}$ & Total partidas & Partidas Ang \\
\hline D-0 & 2582 & 486 \\
D-5 & 2420 & 504 \\
D-10 & 676 & 190 \\
D-15 & 261 & 104 \\
D-18 & 24 & 14 \\
\hline Total general & 5963 & 1298 \\
\hline
\end{tabular}

Fuente: MINCETUR (2009). 
Al 01 de junio de 2016 todas las partidas fueron liberadas. León (2013) afirmó “Al 2012, más del 95\% de las líneas arancelarias se encuentran desgravadas totalmente. La liberalización total se concentrará en el 2016".

León (2013) afirmó "Los peruanos han comprendido las ventajas que conlleva los TLC para el desarrollo económico del país, ello se refleja en más de 17 acuerdos firmados y vigentes con diversos países".
A continuación, la evolución de las exportaciones desde el 2009 al 2015.

Capítulo 1. Este capítulo comprende 54 partidas, de las cuales solo dos se comercializan. La Tabla 3 muestra dos partidas que dejaron de exportarse. Todas las partidas están siendo desaprovechadas, a pesar del arancel cero. El resto no registra movimiento.

Tabla 3. Animales vivos.

\begin{tabular}{clcccccccc} 
Código & Descripción del producto & $\mathbf{2 0 0 9}$ & $\mathbf{2 0 1 0}$ & $\mathbf{2 0 1 1}$ & $\mathbf{2 0 1 2}$ & $\mathbf{2 0 1 3}$ & $\mathbf{2 0 1 4}$ & $\mathbf{2 0 1 5}$ & Status \\
\hline '0106 & Los demás animales vivos. & 0 & 0 & 1 & 1 & 15 & 0 & 0 & Desaprovechada \\
'0101 & Caballos, asnos, mulos & 3 & 3 & 4 & 7 & 4 & 20 & 0 & Desaprovechada \\
'0103 & Animales vivos especie porcina. & 0 & 0 & 0 & 0 & 0 & 0 & 0 & Desaprovechada \\
'0102 & Animales vivos especie bovina. & 0 & 0 & 0 & 0 & 0 & 0 & 0 & Desaprovechada \\
'0105 & Gallos, gallinas, patos, gansos, & 0 & 0 & 0 & 0 & 0 & 0 & 0 & Desaprovechada \\
'0104 & Animales vivos ovina o caprina, & 0 & 0 & 0 & 0 & 0 & 0 & 0 & Desaprovechada \\
\hline
\end{tabular}

Fuente: Trademap, 2016. En miles de dólares.

Capítulo 2. Carne y despojos comestibles, comprende 257 partidas, ninguna se aprovecha. MINCETUR (2019) Chile importa la partida "20130000 carne bovina deshuesada".

Capítulo 3. El capítulo comprende 328 partidas. La Tabla 4 muestra el comercio con siete partidas; de estas, tres ampliaronla oferta exportable, pero dos de ellas disminuyeron sus exportaciones y solo una logro exportar (pescado fresco o refrigerado - 0302). Además, cuatro partidas que ya se exportaban, continúan exportándose, a pesar que ha decrecido. Solo la partida (pescado seco, salado o en salmuera-0305) incrementó sus exportaciones a US\$ 764. El resto de partidas no registra movimientos.

Tabla 4. Pescados y crustáceos, moluscos y otros.

\begin{tabular}{clcccccccc}
\hline Código & \multicolumn{1}{c}{ Descripción } & $\mathbf{2 0 0 9}$ & $\mathbf{2 0 1 0}$ & $\mathbf{2 0 1 1}$ & $\mathbf{2 0 1 2}$ & $\mathbf{2 0 1 3}$ & $\mathbf{2 0 1 4}$ & $\mathbf{2 0 1 5}$ & Status \\
\hline '0401 & Leche y nata (crema), sin concen & 1 & 29 & 0 & 0 & 0 & 10 & 33 & Aprovechada \\
'0402 & Leche y nata (crema), concentra & 1795 & 1849 & 2086 & 2696 & 3694 & 3612 & 4065 & Aprovechada \\
'0403 & Suero de mantequilla; leche y na & 0 & 0 & 3 & 3 & 7 & 33 & 61 & Aprovechada \\
'0406 & Quesos y requesón. & 0 & 23 & 114 & 193 & 202 & 34 & 373 & Aprovechada \\
'0407 & Huevos de ave con cascara (casc & 0 & 0 & 0 & 0 & 0 & 32 & 0 & Aprovechada \\
'0408 & Huevos de ave sin cascara (casc & 0 & 0 & 9 & 80 & 478 & 811 & 586 & Aprovechada \\
\hline
\end{tabular}

Fuente: Trademap, 2016. En miles de dólares.

Capítulo 4. El capítulo comprende 281 partidas. La Tabla 5 muestra el comercio con seis partidas, de las cuales cuatro ampliaron la oferta exportable y dos disminuyeron sus exportaciones; dos lograron incrementar como el suero de mantequillas US\$ 61 y quesos Enero- junio 2021 y requesón US\$ 373. Además, dos partidas que ya eran exportadas e incrementaron sus exportaciones: leche y nata sin concentrar US\$ 33 y sin concentrar US\$ 4065. No son aprovechadas: miel natural, lacto sueros, mantequillas y demás, que el Perú sí exporta. 
Tabla 5. Leche y productos lácteos huevos de ave.

\begin{tabular}{clcccccccc}
\hline Código & \multicolumn{1}{c}{ Descripción } & $\mathbf{2 0 0 9}$ & $\mathbf{2 0 1 0}$ & $\mathbf{2 0 1 1}$ & $\mathbf{2 0 1 2}$ & $\mathbf{2 0 1 3}$ & $\mathbf{2 0 1 4}$ & $\mathbf{2 0 1 5}$ & Status \\
\hline '0401 & Leche y nata (crema), sin concen & 1 & 29 & 0 & 0 & 0 & 10 & 33 & Aprovechada \\
'0402 & Leche y nata (crema), concentra & 1795 & 1849 & 2086 & 2696 & 3694 & 3612 & 4065 & Aprovechada \\
'0403 & Suero de mantequilla; leche y na & 0 & 0 & 3 & 3 & 7 & 33 & 61 & Aprovechada \\
'0406 & Quesos y requesón. & 0 & 23 & 114 & 193 & 202 & 34 & 373 & Aprovechada \\
'0407 & Huevos de ave con cascara (casc & 0 & 0 & 0 & 0 & 0 & 32 & 0 & Aprovechada \\
'0408 & Huevos de ave sin cascara (casc & 0 & 0 & 9 & 80 & 478 & 811 & 586 & Aprovechada \\
\hline
\end{tabular}

Fuente: Trademap, 2016. En miles de dólares.

Capítulo 5. Los demás productos de origen animal. El capítulo comprende 20 partidas, de las cuales solo dos se han exportado; la 0506 solo se exporto en el 2009 y la 0511 hasta el 2013. El resto no registra movimiento.

Capítulo 6. El capítulo comprende 40 partidas. La Tabla 6 muestra las cuatro partidas que son aprovechadas; dos de ellas ampliaron la oferta exportable (las demás plantas vivas y la partida follaje, hojas ramas y demás partes de plantas). Asimismo, una partida semantuvo igual y otra decreció en sus exportaciones, respecto al 2015. El resto no registra movimiento.

Tabla 6. Leche y productos lácteos huevos de ave.

\begin{tabular}{rlrrrrrrrr}
\hline Código & \multicolumn{1}{c}{ Descripción } & $\mathbf{2 0 0 9}$ & $\mathbf{2 0 1 0}$ & $\mathbf{2 0 1 1}$ & $\mathbf{2 0 1 2}$ & $\mathbf{2 0 1 3}$ & $\mathbf{2 0 1 4}$ & $\mathbf{2 0 1 5}$ & Status \\
\hline '0601 & $\begin{array}{l}\text { Bulbos, cebollas, tubérculos, } \\
\text { raíces tuberosas, turiones }\end{array}$ & 11 & 13 & 23 & 25 & 29 & 33 & 33 & Aprovechada \\
'0602 & $\begin{array}{l}\text { Las demás plantas vivas } \\
\text { (incluidas sus raíces), esquejes }\end{array}$ & 0 & 0 & 0 & 0 & 0 & 0 & 3 & Aprovechada \\
'0603 & $\begin{array}{l}\text { Flores y capullos, cortados para } \\
\text { ramos o adornos, frescos, secos, }\end{array}$ & 1 & 6 & 102 & 241 & 350 & 423 & 275 & Aprovechada \\
'0604 & $\begin{array}{l}\text { Follaje, hojas, ramas y demás } \\
\text { partes de plantas, sin flores }\end{array}$ & 0 & 59 & 0 & 20 & 41 & 4 & 42 & Aprovechada \\
\hline
\end{tabular}

Fuente: Trademap, 2016. En miles de dólares.

Capítulo 7. El capítulo comprende 108 partidas. La Tabla 7 muestra las 12 partidas comercializadas, pero solo 11 se aprovecharon del 2009 al 2015 e incrementaron sus exportaciones, como tomates frescos o refrigerados, cebollas y chayotes, zanahorias, hortalizas y las demás hortalizas, incluyendo las silvestres, frescas o refrigeras o cocidas, así como en conserva, las hortalizas secas, de vaina y desvainadas y, finalmente, las raíces de yuca (mandioca). Una partida amplio la oferta exportable: tomates frescos o refrigerados. Siete partidas aumentaron sus exportaciones y cuatro no lo lograron, pero se exportaron. Por ejemplo, la partida 0707 (pepinos y pepinillos, frescos y congelados) presenta la mayor variación de volumen exportado, paso de USD 1 a US\$ 46.

Los productos más exportados fueron los de la partida 0708 (hortalizas conservadas temporalmente), alcanzando un total de US\$ 6,497. La partida papas siempre se exporto, pero decreció en el 2015. Entre las partidas desaprovechas se encuentran las coles, incluidos los repollos, coliflores y las lechugas, etc.; el resto no registra movimiento.

Ccoa (2017) resaltó la importancia de las aceitunas "las aceitunas conservadas o preparadas (productos agropecuarios no tradicionales) representan el mayor sector que exportó en el 2014, por lo que las agroexportaciones en la Región de Tacna, son de 
vital importancia para la economía de dicha región". MINCETUR (2019), en cifras de SUNAT resaltó "0711200000 Aceitunas conservadas provisionalmente todavía impropias para el consumo inmediato".
Asimismo, resaltó la exportación de la partida "07112010 hortalizas conservadas provisionalmente en salmuera (p. 94).

Tabla 7. Legumbres y hortalizas, plantas, raíces.

\begin{tabular}{|c|c|c|c|c|c|c|c|c|c|}
\hline Código & Descripción & 2009 & 2010 & 2011 & 2012 & 2013 & 2014 & 2015 & STATUS \\
\hline '0701 & Papas (patatas) frescas o refrige. & 2 & 2 & 2 & 1 & 1 & 0 & 1 & Desaprovechada \\
\hline '0702 & Tomates frescos o refrigerados. & 0 & 0 & 22 & 56 & 40 & 309 & 299 & Aprovechada \\
\hline '0703 & Cebollas, chalotes, ajos, puerros & 507 & 306 & 181 & 398 & 2795 & 506 & 1537 & Aprovechada \\
\hline '0706 & $\begin{array}{l}\text { Zanahorias, nabos, remolachas } \\
\text { para ensalada, salsifies, }\end{array}$ & 2 & 3 & 6 & 15 & 7 & 10 & 13 & Aprovechada \\
\hline '0707 & Pepinos y pepinillos, frescos o re & 2 & 18 & 13 & 17 & 37 & 6 & 46 & Aprovechada \\
\hline '0708 & $\begin{array}{l}\text { Hortalizas (incluso silvestres) de } \\
\text { vaina, aunque estén desvainada }\end{array}$ & 101 & 274 & 561 & 524 & 452 & 356 & 473 & Aprovechada \\
\hline '0709 & $\begin{array}{l}\text { Las demás hortalizas (incluso } \\
\text { silvestres), frescas o }\end{array}$ & 1015 & 1157 & 1739 & 2039 & 2324 & 2716 & 1643 & Aprovechada \\
\hline '0710 & $\begin{array}{l}\text { Hortalizas (incluso silvestres), } \\
\text { aunque estén cocidas en agua o }\end{array}$ & 173 & 220 & 1005 & 1325 & 930 & 835 & 947 & Aprovechada \\
\hline '0711 & $\begin{array}{l}\text { Hortalizas (incluso silvestres) } \\
\text { conservadas provisionalmente }\end{array}$ & 881 & 2406 & 3945 & 5054 & 5310 & 7191 & 6497 & Aprovechada \\
\hline '0712 & $\begin{array}{l}\text { Hortalizas (incluso silvestres) } \\
\text { secas, bien cortadas en trozos o }\end{array}$ & 148 & 166 & 223 & 384 & 316 & 303 & 280 & Aprovechada \\
\hline '0713 & $\begin{array}{l}\text { Hortalizas (incluso silvestres) de } \\
\text { vaina secas desvainadas, }\end{array}$ & 129 & 148 & 101 & 84 & 104 & 172 & 147 & Aprovechada \\
\hline '0714 & $\begin{array}{l}\text { Raíces de yuca (mandioca), } \\
\text { arrurruz o salep, aguaturmas }\end{array}$ & 73 & 114 & 223 & 210 & 336 & 571 & 579 & Aprovechada \\
\hline
\end{tabular}

Fuente: Trademap, 2016. En miles de dólares.

Capítulo 8. El capítulo comprende 135 partidas. La Tabla 8 muestra las 11 partidas comercializadas, de las cuales

10 son aprovechadas, de las cuales cuatro ampliaron la oferta exportable: los demás frutos de cáscara frescos o secos, bananas o plátanos, las demás frutas u otros o frutos y conservados; los bananos cavendis valery. Seis partidas aumentaron considerablemente sus exportaciones y solamente los agrios no lograron incrementar, pero se exporto
US\$ 3 227. Las partidas que están siendo desaprovechadas son manzanas, peras y membrillos, así como chabacanos y cortezas de agrios (cítricos); el resto no registra movimientos. MINCETUR (2019) en cifras de SUNAT resaltó “0811909900, Las demás frutas y otros frutos sin cocer o cocidos en agua o vapor, congelados sin adición de azúcar u otro edulcorante". Asimismo, resaltó la partida 08045000 mangos frescos" (p. 94). 
Tabla 8. Frutos comestibles; cortezas de agrios.

\begin{tabular}{clcccccccc}
\hline Código & \multicolumn{1}{c}{ Descripción } & $\mathbf{2 0 0 9}$ & $\mathbf{2 0 1 0}$ & $\mathbf{2 0 1 1}$ & $\mathbf{2 0 1 2}$ & $\mathbf{2 0 1 3}$ & $\mathbf{2 0 1 4}$ & $\mathbf{2 0 1 5}$ & Status \\
\hline '0801 & Cocos, nueces del Brasil y nueces de & 34 & 24 & 22 & 37 & 65 & 59 & 115 & Aprovechada \\
'0802 & Los demás frutos de cascara frescos & 0 & 29 & 0 & 0 & 0 & 0 & 9 & Aprovechada \\
'0803 & Bananas o plátanos, frescos o secos. & 0 & 0 & 16 & 26 & 12 & 10 & 0 & Desaprovechada \\
'0804 & Dátiles, higos, pinas (ananás), paltas & 502 & 1174 & 2965 & 2713 & 3917 & 7153 & 16584 & Aprovechada \\
'0805 & Agrios (cítricos) frescos o secos. & 980 & 1320 & 1809 & 1951 & 2419 & 3275 & 3227 & Aprovechada \\
'0806 & Uvas, frescas o secas, incluidas las & 121 & 267 & 748 & 36 & 200 & 0 & 420 & Aprovechada \\
'0807 & Melones, sandias y papayas, frescos. & 304 & 237 & 271 & 412 & 794 & 646 & 940 & Aprovechada \\
'0810 & Las demás frutas u otros frutos, fresc & 0 & 0 & 1 & 0 & 1 & 0 & 561 & Aprovechada \\
'0811 & Frutas y otros frutos, sin cocer o coci & 1324 & 1122 & 2096 & 3733 & 5821 & 7586 & 15773 & Aprovechada \\
'0812 & Frutas y otros frutos, conservados & 0 & 0 & 0 & 0 & 0 & 0 & 1 & Aprovechada \\
'0813 & Frutas y otros frutos, secos, excepto & 1 & 0 & 28 & 0 & 19 & 0 & 32 & Aprovechada \\
\hline
\end{tabular}

Fuente: Trademap, 2016. En miles de dólares.

Ccoa(2017)también resaltó aquellos productos que incrementaron sus exportaciones a Chile, "uvas frescas, mangos y mangostanes, bananas, etc.”. El MINCETUR (2018) indicó que las piñas, en sus diversas presentaciones, poseen oportunidad comercial en Chile. MINCETUR (2019) en cifras de SUNAT, indicó como los más exportados a Chile " 08119090 frutas y frutos secos sin cocer - los demás y 08044019 paltas frescas".

Capítulo 9. El capítulo comprende 43 partidas. La Tabla 9 muestra siete partidas comercializadas, solo tres aprovechadas (té, yerba mate y jengibre, azafrán, cúrcuma, tomillo, etc.). Las dos primeras ampliaron la oferta exportable, así como la vainilla, aunque dejo de exportarse. Las cuatro partidas restantes están siendo desaprovechadas porque han decrecido en sus exportaciones, por ejemplo, el café se redujo de US\$ 2422 a US\$ 996, así como la pimienta del género piper y las semillas de anís (no han variado respecto al 2009). Se encuentran varias partidas desaprovechadas, como: la canela y flores de canelero; el clavo y la nuez moscada, macis, amomos y cardamomos. El resto no registra movimientos.

Tabla 9. Café, té, yerba mate y especias.

\begin{tabular}{llccccccccc}
\hline Código & \multicolumn{1}{c}{ Descripción } & $\mathbf{2 0 0 9}$ & $\mathbf{2 0 1 0}$ & $\mathbf{2 0 1 1}$ & $\mathbf{2 0 1 2}$ & $\mathbf{2 0 1 3}$ & $\mathbf{2 0 1 4}$ & $\mathbf{2 0 1 5}$ & Status \\
\hline '0901 & $\begin{array}{l}\text { Café, incluso tostado o } \\
\text { descafeinado; cascara y }\end{array}$ & 2422 & 323 & 2035 & 3855 & 1421 & 1430 & 996 & Desaprovechada \\
'0902 & $\begin{array}{l}\text { Te, incluso aromatizado. } \\
\text { '0903 }\end{array}$ & $\begin{array}{l}\text { Yerba mate. } \\
\text { '0 }\end{array}$ & 0 & 1 & 0 & 1 & 1 & 0 & 5 & Aprovechada \\
'0904 & $\begin{array}{l}\text { Pimienta del genero piper; frutos } \\
\text { de los géneros capsicum }\end{array}$ & 1285 & 464 & 1571 & 1304 & 1095 & 707 & 783 & Desaprovechada \\
'0905 & $\begin{array}{l}\text { Vainilla. } \\
\text { '0909 }\end{array}$ & $\begin{array}{l}\text { Semillas de anís, badiana, hinojo, } \\
\text { cilantro, comino o alcaravea; }\end{array}$ & 4 & 1 & 1 & 0 & 8 & 0 & 4 & Desaprovechada \\
'0910 & $\begin{array}{l}\text { Jengibre, azafrán, cúrcuma, } \\
\text { tomillo, hojas de laurel, curry }\end{array}$ & 106 & 143 & 285 & 230 & 140 & 241 & 365 & Aprovechada \\
\hline
\end{tabular}

Fuente: Trademap, 2016. En miles de dólares.

Capítulo 10. El capítulo comprende 55 partidas. La Tabla 10 muestra las siete partidas comercializadas, de las cuales solo cuatro son aprovechadas (cebada, maíz, arroz y alforfón, mijo y alpiste; los demás cereales). Tres partidas ampliaron la oferta exportable, pero una de ellas ya no se exporta (avena). La partida alforfón, mijo y alpiste incrementó sus exportaciones al $1558 \%$. El trigo y morcajo decrecieron y dejaron de exportarse, también el sorgo se exportó hasta el 2009, así como la avena y el centeno no se exporto jamás. 
Tabla 10. Cereales.

\begin{tabular}{clcccccccc}
\hline Código & Descripción del producto & $\mathbf{2 0 0 9}$ & $\mathbf{2 0 1 0}$ & $\mathbf{2 0 1 1}$ & $\mathbf{2 0 1 2}$ & $\mathbf{2 0 1 3}$ & $\mathbf{2 0 1 4}$ & $\mathbf{2 0 1 5}$ & Status \\
\hline '1001 & Trigo y morcajo (tranquillón). & 2 & 1 & 1 & 2 & 2 & 4 & 0 & Desaprovechada \\
'1003 & Cebada. & 0 & 0 & 0 & 0 & 1 & 1 & 1 & Aprovechada \\
'1004 & Avena. & 0 & 0 & 2 & 1 & 0 & 0 & 0 & Desaprovechada \\
'1005 & Maíz. & 36 & 39 & 44 & 179 & 192 & 375 & 105 & Aprovechada \\
'1006 & Arroz. & 0 & 27 & 0 & 0 & 9 & 32 & 53 & Aprovechada \\
'1007 & Sorgo de grano (granífero). & 19 & 0 & 0 & 0 & 0 & 0 & 0 & Desaprovechada \\
'1008 & Alforfón, mijo y alpiste; & 65 & 56 & 252 & 232 & 165 & 1043 & 1078 & Aprovechada \\
\hline
\end{tabular}

Fuente: Trademap, 2016. En miles de dólares.

Capítulo 11. El capítulo comprende 80 partidas. La Tabla 11 muestra las siete partidas comercializadas, de las cuales seis son aprovechadas; algunas de ellas ampliaron la oferta exportable (cuatro), a pesar que el almidón y fécula ya no se exporta. De las tres partidas restantes, una de ellas aumento las exportaciones (harina, sémola y polvo de las hortalizas). El resto de partidas decreció (harina de trigo o de morcajo y grano de cereales trabajados de otro modo). Llama la atención las partidas desaprovechadas (grañones, sémola y pallets de cereales; así como harina, sémola, polvo, copos, gránulos y pellets) jamás se exportaron y la partida almidón y fécula que dejo de exportarse.

Tabla 11. Productos de la molinera; malta; almidón.

\begin{tabular}{rlrrrrrrrr}
\hline Código & \multicolumn{1}{c}{ Descripción del producto } & $\mathbf{2 0 0 9}$ & $\mathbf{2 0 1 0}$ & $\mathbf{2 0 1 1}$ & $\mathbf{2 0 1 2}$ & $\mathbf{2 0 1 3}$ & $\mathbf{2 0 1 4}$ & $\mathbf{2 0 1 5}$ & Status \\
\hline '1101 & $\begin{array}{l}\text { Harina de trigo o de morcajo } \\
\text { tranquillón). }\end{array}$ & 193 & 267 & 1413 & 344 & 1394 & 1355 & 358 & Aprovechada \\
'1102 & $\begin{array}{l}\text { Harina de cereales, excepto de } \\
\text { trigo o de morcajo (tranquillón). }\end{array}$ & 0 & 0 & 0 & 0 & 5 & 7 & 46 & Aprovechada \\
'1104 & $\begin{array}{l}\text { Granos de cereales trabajados de } \\
\text { otro modo }\end{array}$ & 8 & 2 & 13 & 31 & 22 & 87 & 44 & Aprovechada \\
'1106 & $\begin{array}{l}\text { Harina, sémola y polvo de las } \\
\text { hortalizas de la partida }\end{array}$ & 15 & 9 & 21 & 31 & 33 & 40 & 59 & Aprovechada \\
'1107 & $\begin{array}{l}\text { Malta (de cebada u otros } \\
\text { cereales), incluso tostada. }\end{array}$ & 0 & 0 & 0 & 0 & 78 & 0 & 1 & Aprovechada \\
'1108 & $\begin{array}{l}\text { Almidón y fécula; inulina. } \\
\text { Gluten de trigo, incluso seco. }\end{array}$ & 0 & 53 & 0 & 439 & 1 & 0 & 0 & $\begin{array}{l}\text { Desaprovechada } \\
\text { Aprovechada }\end{array}$ \\
\hline
\end{tabular}

Fuente: Trademap, 2016. En miles de dólares.

Capítulo 12. El capítulo comprende 68 partidas. La Tabla 12 muestra las siete partidas comercializadas, de las cuales dos son aprovechadas y 4 ampliaron la oferta exportable, a pesar que dos dejaron de exportarse (habas y harina de semillas).
El resto decrecieron en sus exportaciones, respecto al 2015. Las partidas cacahuates; semillas de lino, semillas de nabo o colza; conos de lúpulo frescos o secos; paja y cascabillos de cereales; y nabos forrajeros jamás se han exportado. 
Tabla 12. Semillas y frutos oleaginosos; semillas.

\begin{tabular}{|c|c|c|c|c|c|c|c|c|c|}
\hline Código & Descripción del producto & 2009 & 2010 & 2011 & 2012 & 2013 & 2014 & 2015 & Status \\
\hline '1201 & $\begin{array}{l}\text { Habas (porotos, frijoles, } \\
\text { frejoles) de soja (soya), }\end{array}$ & 0 & 2 & 0 & 0 & 1 & 1 & 0 & Desaprovechada \\
\hline '1206 & $\begin{array}{l}\text { Semilla de girasol, incluso } \\
\text { quebrantada. }\end{array}$ & 0 & 1 & 18 & 0 & 0 & 0 & 14 & Aprovechada \\
\hline '1207 & $\begin{array}{l}\text { Las demás semillas y } \\
\text { frutos oleaginosos, }\end{array}$ & 0 & 0 & 0 & 6 & 34 & 0 & 579 & Aprovechada \\
\hline '1208 & $\begin{array}{l}\text { Harina de semillas o de } \\
\text { frutos oleaginosos, }\end{array}$ & 0 & 0 & 0 & 2 & 1 & 1 & 0 & Desaprovechada \\
\hline '1209 & $\begin{array}{l}\text { Semillas, frutos y esporas, } \\
\text { para siembra. }\end{array}$ & 530 & 427 & 246 & 670 & 294 & 30 & 57 & Desaprovechada \\
\hline '1211 & $\begin{array}{l}\text { Plantas, partes de plantas, } \\
\text { semillas y frutos }\end{array}$ & 2126 & 1618 & 2036 & 3374 & 3811 & 1874 & 1196 & Desaprovechada \\
\hline '1212 & $\begin{array}{l}\text { Algarrobas, algas, } \\
\text { remolacha azucarera }\end{array}$ & 171 & 79 & 46 & 1 & 28 & 14 & 90 & Desaprovechada \\
\hline
\end{tabular}

Fuente: Trademap, 2016. En miles de dólares.

Capítulo 13. Gomas, resinas y demás jugos y extractos. El capítulo comprende 13 partidas. Sin embargo, solo dos muestran movimiento; una amplio la oferta exportable, pero dejode exportarse (goma laca, resinas) y la otra partida incremento sus exportaciones, (jugos y extractos vegetales).

Capítulo 14. Materias trenzables, demás productos de origen vegetal. El capítulo comprende cinco partidas. Sin embargo, solo dos se aprovechan y muestran aumento en sus exportaciones (materias vegetales 1401), amplio la oferta exportable. La partida 1404 aumento en $138 \%$ sus exportaciones (US\$ 119), respecto al 2015. El resto de partidas no registran movimientos.

Capítulo 15. Grasas y aceites animales o vegetales. El capítulo comprende 124 partidas, de las cuales 14 se comercializan. Las partidas que ampliaron la oferta exportable son ocho, a pesar que algunas dejaron de exportarse como el aceite de cacahuate. Asimismo, siete partidas son aprovechadas e incrementaron sus exportaciones (grasas y aceites; lasdemás grasas y aceites; aceite de soja; aceite de palma; aceite de coco; grasas o aceites animales o vegetales; y glicerol en bruto. Otra partida aprovechada es la margarina, la cual era exportada y aumento sus exportaciones en un $295 \%$. Otras partidas aun no logran incrementar sus exportaciones (aceite deoliva y sus fracciones; las demás grasas $\mathrm{y}$ aceites vegetales fijos; grasas y aceites animales o vegetales; y ceras vegetales). El resto de partidas han sido y continúan siendo exportadas, pero no logran incrementar sus exportaciones, como aceite de oliva (US\$ 53); las demás grasas (US\$ 7) y grasas y aceites animales o vegetales (US\$ 3,804). Entre las partidas desaprovechadas totalmente se encuentran la grasa de cerdo; grasa de animales ovina, porcina; estearina solar;grasa de lana y sustancias grasas; los demás aceites y sus fracciones; aceites de girasol; aceites de nabo o colza; y degras; el resto no registran movimientos. Rodríguez (2016, p. 99) resaltó entre las principales exportaciones de 19942014 "1504201000 grasas y aceites de pescado y sus fracciones excepto aceite de hígado en bruto". MINCETUR (2019, p. 30) en cifras de SUNAT resaltó " 1511900000 , Aceite de palma y sus fracciones incluso refinado, pero sin modificar químicamente". Asimismo, MINCETUR (2019, p. 93) Chile importa la partida "15079090 aceite de soja y sus fracciones", la cual es desaprovechada.

Capítulo 16. Preparaciones de carne, pescado o crustáceos. El capítulo comprende 92 partidas, de las cuales tres se comercializan. Solo una partida amplía la oferta exportable (1602), pero dejo de exportarse, siendo desaprovechada. Solo una partida es aprovechada porque incremento sus exportaciones (crustáceos, moluscos y demás 
invertebrados). La partida preparaciones y conservas de pescado no logran incrementar sus exportaciones. Las partidas embutidas y productos similares de carne y extractos y jugos de carne, pescado o crustáceos no se exportan, son desaprovechadas.

Capítulo 17. Azúcares y artículos de confitería. El capítulo comprende 50 partidas, de las cuales cuatro se comercializan. Las partidas que ampliaron la oferta exportable son tres, pero dos de ellas dejaron de exportarse. Las partidas que son aprovechadas son los demás azucares US\$ 165 y los artículos de confitería US\$2,749. El resto de partidas no son aprovechadas.

Capítulo 18. Cacao y sus preparaciones. El capítulo comprende 31 partidas, de las cuales cinco se comercializan. Ampliaron la oferta exportable el cacao en grano y manteca, grasa y aceite de cacao. El resto (cuatro) han incrementado sus exportaciones, siendo aprovechadas (cacao en polvo y chocolate y demás); una partida decreció en sus exportaciones (pasta de cacao). La partida desaprovechada es la cáscara, películas y demás residuos de cacao no registro exportaciones; el resto no registra movimiento, son desaprovechados.

Capítulo 19. Preparados a base de cereales, harina. El capítulo comprende 53 partidas, de las cuales cuatro se comercializan. Todas las partidas han incrementado sus exportaciones, indicando que se están aprovechando. La única partida desaprovechada es la 1903 (tapioca), no registro exportaciones; el resto no registra movimiento, son desaprovechadas. Rodríguez (2016) resaltó entre las principales exportaciones de 1994-2014 "1902190000 demás pastas alimenticias sin cocer, rellenar ni preparar de otra forma", confirmadopor MINCETUR (2019, p. 24), en cifras de SUNAT. MINCETUR (2015) "posee arancel preferencial" por TLC. Asimismo, MINCETUR (2018) sostuvo que la partida quinua, en sus diversas presentaciones, posee oportunidad comercial en Chile.

Capítulo 20. Preparados de legumbres, hortalizas, frutos. El capítulo comprende 373 partidas, de las cuales ocho se comercializan. Ampliaron la oferta exportable solo dos partidas (tomates preparados o conservados y las demás hortalizas preparadas o conservadas). Vienen siendo aprovechadas las hortalizas US\$ 284; las demás hortalizas US\$ 4,616; y frutas u otros frutos US\$2,335. Otras partidas se exportan, pero no aumentaron sus exportaciones, confituras y jaleas US\$ 10 ; y jugos de frutas US\$ 677. La partida hortalizas, frutas u otros frutos o sus cortezas dejo de exportarse; las setas y demás hongos jamás se exportaron. El resto no registra movimiento.

Capítulo 21. Preparaciones alimenticias diversas. El capítulo comprende 50 partidas, de las cuales seis se comercializan. Solo dos ampliaron la oferta exportable (extractos, esencias y concentrados US\$ 14 y helados, dejo de exportarse. El resto han aumentado sus exportaciones en relación al año 2009 (preparaciones para sopas y preparaciones alimenticias). Las levaduras dejaron de exportarse en el buen promedio, así como la partida preparaciones para salsas fue la que más creció en sus exportaciones a US\$ 2,707. El resto de partidas no registra movimiento. MINCETUR (2019) Chile importa la partida "21069090 preparaciones alimenticias y 21061010 preparaciones alimenticiasconcentrados de proteínas", las cuales no son aprovechadas.

Capítulo 22. Bebidas, líquidos alcohólicos y vinagre. El capítulo comprende 177 partidas, de las cuales ocho se comercializan. Solo tres ampliaron la oferta exportable (vino de uvas frescas; las demás bebidas fermentadas; y vinagre y sucedáneos) los cuales decrecieron en sus exportaciones. Las partidas (tres) agua, incluidas la mineral y gaseada incremento sus exportaciones a US\$ 4,654; la cerveza malta US\$ 6,525; y alcohol etílico US\$ 3,034; todas ellas aprovechadas. MINCETUR (2019), en cifras de SUNAT, resaltó "2203000000 Cerveza de malta". La partida 2201 decreció, pero continúa exportándose. La partida alcohol etílico sin desnaturalizar dejo de exportarse; el vermut no se exporto jamás. El resto no registra movimiento. 
Capítulo 23. Residuos, desperdicios de las industrias alimentarias. El capítulo comprende 62 partidas, de las cuales solamente dos se comercializan y son aprovechadas (harinas, polvo y pallets de carne US\$46,533 y la partida preparaciones del tipo de las utilizadas para la alimentación US\$ 115). El resto son desaprovechadas, no registran movimiento. Rodríguez (2016) resaltó entre las principales exportaciones de 1994-2014 "2301201100 con un contenido de grasa superior a $2 \%$ en peso". También consideró " 2301201010 harina de pescado sin desgrasar, impropiopara la alimentación humana, con contenido de grasa mayor a $2 \%$ en peso".

MINCETUR (2019) Chile importalas partidas "23040020 (harinas de tortasy residuos sólidos), 23040030 (Tortas y demás residuos sólidos-pellets), 23040030 (alimentos para animales en bolsas o sacos) y 23091019 alimentos para animales - los demás)" que no son aprovechados por Perú.

Capítulo 24. Tabaco y sucedáneos del tabaco elaborados. El capítulo comprende 31 partidas, de las cuales solo una se comercializa, el tabaco en rama o sin elaborar (2401). Lamentablemente, esta partida no se exportó en el 2015. El resto de partidas no se exportaron jamás y son desaprovechadas, no registran movimiento.

Se identificaron 88 partidas que son aprovechadas, al haberse iniciado en las exportaciones o porque las incrementaron desde la entrada en vigencia (2009) hasta el año 2015. Entre las principales partidas se encontró: productos a base de cereales; flores y capullos; extracto de malta; margarinas; dátiles; leche y nata (crema); frutas y otros frutos; pepinos y pepinillos; alforfón, mijo y alpiste; filetes y demás carnes de pescado; grasas y aceites animales o vegetales; cerveza de malta; harina, polvo y pallets de carne; raíces de yuca; artículos de confitería sin cacao; etc.

Por otro lado, 2411 partidas no se aprovechan, porque decrecieron en sus exportaciones, porque dejaron de exportarse o bien, porque jamás se exportaron. Finalmente, 51 partidas ampliaron la oferta exportable, pero muchas de ellas dejaron de exportarse, se mantienen igual $\mathrm{O}$ decrecieron sus exportaciones, como se muestra en la Tabla 13.

Tabla 13. Principales productos desaprovechados.

\begin{tabular}{|c|c|c|c|}
\hline Código & Descripción del producto & Código & Descripción del producto \\
\hline '0201 & $\begin{array}{l}\text { Carne de animales de la especie bovina, } \\
\text { fresca o refrigerada. }\end{array}$ & '0908 & $\begin{array}{l}\text { Nuez moscada, macis, amomos y } \\
\text { cardamomos. }\end{array}$ \\
\hline '0203 & $\begin{array}{l}\text { Carne de animales de la especie porcina, } \\
\text { fresca, refrigerada o congela }\end{array}$ & '1208 & $\begin{array}{l}\text { Harina de semillas o de frutos oleaginosos, } \\
\text { excepto la harina de mostaza }\end{array}$ \\
\hline '0405 & $\begin{array}{l}\text { Mantequilla y demás materias grasas de la } \\
\text { leche; pastas lácteas para u }\end{array}$ & '1508 & $\begin{array}{l}\text { Aceite de cacahuate (cacahuete, maní) y sus } \\
\text { fracciones, incluso refina }\end{array}$ \\
\hline '0407 & $\begin{array}{l}\text { Huevos de ave con cascara (cascaron), } \\
\text { frescos, conservados o cocidos. }\end{array}$ & '1510 & $\begin{array}{l}\text { Los demás aceites y sus fracciones obtenidos } \\
\text { exclusivamente de aceituna. } \\
\text { Aceites de girasol, cártamo o algodón, y sus }\end{array}$ \\
\hline '0409 & $\begin{array}{l}\text { Miel natural. } \\
\text { Cerdas de cerdo o de jabalí; pelo de tejón y }\end{array}$ & '1512 & $\begin{array}{l}\text { fracciones, incluso refinada } \\
\text { Ceras vegetales (excepto los triglicéridos), }\end{array}$ \\
\hline '0502 & demás pelos de cepillaría & '1521 & $\begin{array}{l}\text { cera de abejas o de otros } \\
\text { Embutidos y productos similares de carne, }\end{array}$ \\
\hline '0803 & Bananas o plátanos, frescos o secos. & '1601 & $\begin{array}{l}\text { despojos o sangre; preparación } \\
\text { Azúcar de caña o de remolacha y sacarosa }\end{array}$ \\
\hline '0808 & Manzanas, peras y membrillos, frescos. & '1701 & químicamente pura, en estado \\
\hline '0905 & Vainilla. & '1802 & $\begin{array}{l}\text { Cascara, películas y demás residuos de cacao. } \\
\text { Setas y demás hongos y trufas, preparadas o }\end{array}$ \\
\hline '0906 & Canela y flores de canelero. & '2003 & conservadas (excepto en \\
\hline
\end{tabular}

Fuente: Trademap, 2016. 


\section{Conclusiones}

El Tratado de Libre Comercio es una herramienta que puede ser o no aprovechada por los exportadores. El TLC Perú-Chile, vigente desde marzo de 2009 , en reemplazo del ACE N. 38, podría ser mejor aprovechado, 2411 partidas lo prueban.

Los principales productos exportadosa Chile son materias primas, tales como: desperdicios de la industria alimentaria, frutos comestibles (frescos y cocidos) y productos grasos y aceites animales y vegetales, ceras, etc. El resto de partidas se desaprovechan porque no se exportan, sus exportaciones continúan igual o han decrecido. Se descartan exigencias fitosanitarias de Chile que impidan el comercio entre ambos países; al contrario, Los ministros de Agricultura de ambos países han firmado un acuerdo bilateral para dar inicio con la certificación electrónica en los procedimientos de agro exportación deambos países. La implementación de esta certificación permitirá facilitar el comercio de 96, 000 toneladas de productos exportados, que representan unos 7,000 envíos de Perú a Chile, en promedio al año. La certificación electrónica permite el intercambio de información sobre las condiciones fitosanitarias y la seguridad de los productos agrarios y permitirá agilizar los trámitesde exportación e importación de plantas y productos vegetales entre ambos países, eliminando automáticamente la emisión de documentos para brindar un servicio eficaz, eficiente, ágil, moderno y seguro, inclusive con el medio ambiente. El Tratado posee muchas partidas beneficiadas por diversas canastas, liberadas en su totalidad, culminando la creación de la zona de libre comercio. El Perú debe considerar políticas que incentiven las exportaciones con valor agregado, se debe propiciar una mayor la difusión de los beneficios que provee el Tratado, fortalecer las cadenas asociativas productivas agrarias. Además, se debe profundizar en el análisis de las partidas desaprovechadas, las que no se exportan o han decrecido en sus exportaciones para identificar nuevas oportunidades de negocios o investigar las posibles causas para solucionar, también separar las partidas potenciales de las no potenciales; desarrollar programas de capacitación a productores agropecuarios y exportadores para difundir las ventajas del TLC y sean mejor aprovechados todos los nichos de negocio.

Finalmente, no todas las partidas desaprovechadas constituyen oportunidades de negocio por la poca capacidad productiva o exportadora, insuficiencia en la oferta, etc.

\section{Referencias}

Ccoa, J. 2017. La implementación del Tratado de Libre Comercio Perú-Chile enlos despachos de agro-exportación en el complejo fronterizo de Santa Rosa - Tacna con relación al control aduanero (tesis de magíster). Pontificia Universidad Católica del Perú, Lima, Perú.

Centro de Comercio Internacional. 2016. Trade Map. Disponible en https://www. trademap.org/Index.aspx

Faerlie, A. 2010. TLC y agendas complementarias: balance y lineamientos de propuesta, en: Opciones de política económica en el Perú 2011-2015, edición 1, cap. 9, pp. 275-325. Fondo Editorial -PUCP

Hernández, R.; Fernández, C.; Baptista, P. 2010. Metodología de la Investigación. México: Editorial McGraw Hill

León, L. 2013. Acuerdos Comerciales del Perú. Lima, Perú: Congreso de la República.

MINCETUR. 2009. Tratado de Libre Comercio Perú Chile. Recuperado de http://www.acuerdoscomerciales.gob.pe/

index.php?option=com_content $\&$ view $=$ ca egory\&layout $=$ blog $\& i d=72 \&$ Itemid $=95$

MINCETUR. 2018. Plan de Desarrollo de Mercado de Chile - PDM. Exposición de Gustavo Bedoya del 18.04.2018. Recuperado de

http://export.promperu. gob.pe/Miercoles/Portal/MME/descargar. aspx? archivo=74959AA7-8FE2-4F20-8FD9FC09BF2C46C2.PDF

MINCETUR. 2019. Plan de Desarrollo de Mercado de Chile - PDM. Recuperadode https://www.gob.pe/institucion/mincetur/ informes-publicaciones/285237-plan-dedesarrollo-de-mercado-de-chile 
Morales, R. 2020. La administración del Acuerdo de Libre Comercio firmado entre la República del Perú y la República de Canadá desde la mirada del agronegocio peruano. Natura@economía 5(2):126-143(2020).

Morales, R. 2018. La administración del Tratado de Libre Comercio entre la República del Perú y la Unión Europea desde la mirada del agronegocio. El caso de Alemania. Natura@economía 3(1):29-44(2018).

PROMPERU. 2015. Guía de Mercado de Chile. Recuperado de https:// www.siicex.gob.pe/siicex/resources/ estudio/855935902radE7CBB.pdf

Rodríguez, A. 2016. Perú: acuerdos comerciales y su incidencia sobre el nivel de exportaciones nacionales, periodo 1994-2014 (tesis de pregrado). Universidad Nacional de Trujillo, Trujillo, Perú. 